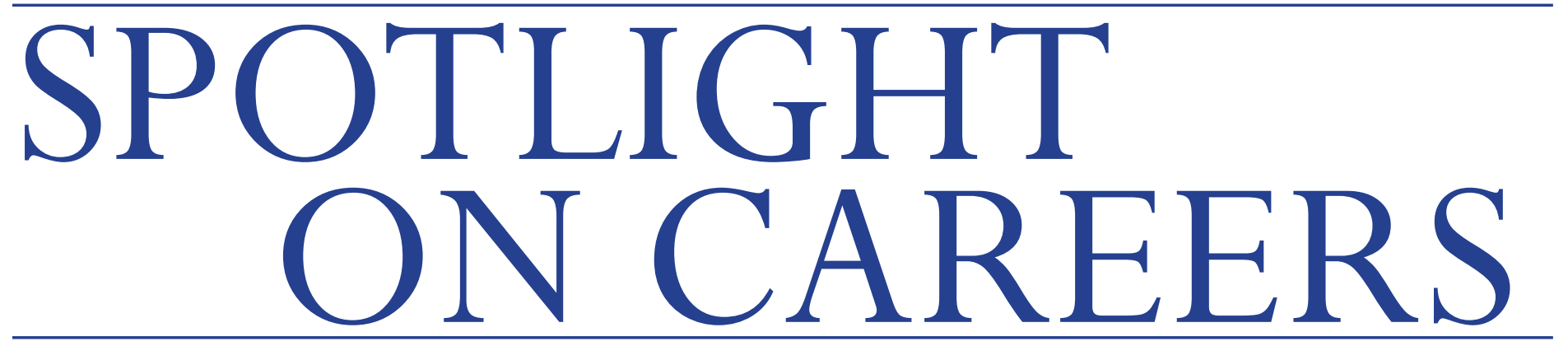

EPIDEMIOLOGY

\title{
Tackling environmental health: from research to government
}

\section{QঊA with Elaina MacIntyre, an epidemiologist with Public Health Ontario and a University of Toronto adjunct professor.}

BY ALISON HOWIE

$\mathbf{E}$

laina MacIntyre is an epidemiologist specialist at Public

Health Ontario and an adjunct professor at the Dalla Lana

School of Public Health at the University of Toronto. MacIntyre acquired a B.Sc. in microbiology and immunology at Dalhousie University in Halifax, Nova Scotia where she was raised. After working for a year, MacIntyre decided to pursue an M.Sc. in occupational and environmental hygiene at the University of British Columbia. Upon completing one year of coursework for her M.Sc., MacIntyre transitioned into a $\mathrm{PhD}$ program where she researched the association between air pollution and childhood ear infections in a cohort of 60,000 babies in British Columbia. She subsequently completed a postdoctoral fellowship at the University of British Columbia while living in Munich, Germany. MacIntyre worked as an environmental epidemiologist at the German Research Center for Environmental Health before returning to Canada, and has been in her current role for seven years.

What led you to pursue a career as an epidemiologist specialist and as a pro- fessor of environmental health, and what path did you take to get here?

I've always felt a close connection to the environment, and I've always been quite passionate about environmental causes. In terms of how my career unfolded, I really had no intention of working in this field. I did my undergraduate degree in microbiology and business because I had planned to go into pharmaceutical and disease research. I happened to take an elective environmental health course in the final year of my undergraduate degree, and the course brought up aspects of epidemiology, population health, and preventative medicine, and introduced me to this field of science that really brings together my passion for the environment, and links it to human health and disease. I worked for an epidemiologist for a year and that's when I really got the bug. Once I discovered that there was this world of research that bridged everything together, I was sold. It was just a matter of finding a supervisor who I would want to work with for a number of years doing research that I cared about. It started as an M.Sc. and then evolved into a PhD. I was very

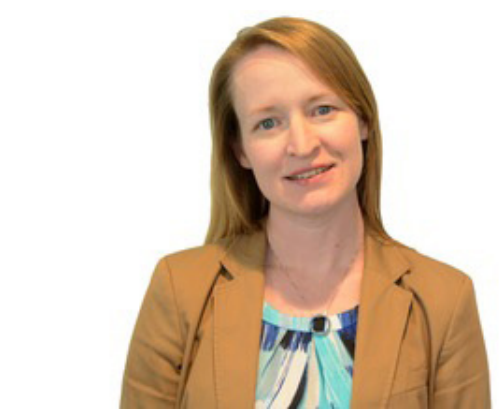

Elaina MacIntyre

lucky to have consistent funding during my $\mathrm{PhD}$, and one of my fellowships required me to work, so I chose to go to Munich, Germany. I really wanted to get experience in a very different environment, and luckily they were doing similar research to the research I had already done with my PhD. When that work placement wrapped up, I found myself really loving the institute and the people I worked with, and that's when I decided to do a post-doctoral fellowship and later decided to stay on as an environmental epidemiologist. My decision to move back was more for my family, rather than a career move. I had been keeping my eyes and ears open for potential opportunities available in Canada for a year before my current job brought me to Toronto. 


\section{What does your average day look like?}

It definitely changes every day. Most days are ones where I'll sit down at my desk and discover that there are new and last-minute things to respond to, and my day doesn't go nearly as planned. I don't like doing the same thing every day, so for me this is perfect. My day usually starts with reading up on new and emerging research in areas where we know there are some misinformation or misunderstanding. In collaboration with a small but diverse team, we decide if we should dig a little deeper and learn more about certain issues. Since Public Health Ontario is a technical and scientific body that provides advice and support to the Ontario government on any topic related to public health, there's really no limit to the kind of topics that I might look at on any given day. Air pollution and water quality are two topics that often come up. Another part of my job involves managing a number of environmental health surveillance projects. This often involves identifying data from outside the health sector, and interpreting them in a way that makes it useful for public health decision making. I'm also an adjunct professor at the University of Toronto, where I co-lead an occupational and environmental health seminar series and present guest lectures.

You had a significant role in the Public Health Ontario report, "Environmental burden of Cancer in Ontario." Can you talk a bit about the relationship between the environment and cancer?

What's often not well recognized is that we're connected to the environment around us every second of our life. We're breathing air, drinking water, eating food and walking outside in the sun - these exposures never end, and we often don't give them a lot of thought. Decision makers often come to us and say, "we recognize that environmental health is increasingly important, but we want to know what aspect of the environment is most important for the health of our population." What we set out to do with the report was to address this question and to identify the carcinogens in our environment that we think cause the most cancer. One of the key findings was that the top two causes of environmental cancer, at least those that are most significant in Ontario, are not things that are man-made. Sunlight and radon are both entirely natural, and there are many good, well-documented ways to protect yourself from them. We often identify man-made sources, such as factory emissions, as top environmental concerns, so I think the findings from this report were really eye-opening for many.

\section{Do you feel that enough is being done in Canada to mitigate the health effects of common environmental risk factors?}

I think our real strength right now is that we are improving our understanding of how the environment impacts our health. The decisions that have to be made in terms of protecting population health are not always clear, but the first step is to just understand what's going on. Going back to the burden of cancer report, one of the reasons why the man-made carcinogens may not have been as significant could be that in the last few decades, we've done a good job at controlling some of those things. We've gotten really good at developing field to pursue it. A few decades ago, we thought that the health impacts associated with air pollution were only a problem in certain regions of the world. What we've learned in the last 10 or 20 years is that even in regions like Vancouver, with some of the best air quality in Canada, we see associations between air pollution and poor health. As this knowledge continues, and as we build a greater understanding, I think the field is going to change a lot. But for people like me, that's what makes it so exciting. If you're interested at all, definitely pursue the field. It can be discouraging at times, and it can be hard to get into, but reach out to people who you think are doing exciting work and ask them to mentor you. Part of why I moved from Halifax to Vancouver was because I found someone through publications that I wanted to be my supervisor. I approached him and, luckily, he was willing to take me on. When I talk to colleagues and other people in my field, we all have very similar stories. We found someone we wanted to learn from, they took us under their wing, and the rest is history. Never be timid or hesitant to reach out to people, because we all remember what it was like to be in your shoes.

\section{"Never be timid or hesitant to reach out to people, because we all remember what it was like to be in your shoes."}

controls and engineering technologies that have improved our environment where we traditionally had been concerned. In part, the findings from the burden of cancer report might actually demonstrate that, while there's always going to be more that can be done, we've made good progress already.

\section{Do you have any advice for graduate students interested in pursuing a simi- lar career path?}

I would encourage anyone who has a real passion and curiosity about this 